\title{
Prospects for the use of Multiphase Inverter-fed Asynchronous Drives in the Field of Traction Systems of Railway Vehicles
}

\author{
Andrey V. Brazhnikov ${ }^{\dagger}$ and Ilya R. Belozerov
}

\begin{abstract}
At present among the most important problems in the field of traction systems of railway vehicles are the following: 1) the minimization of the mass-and-overall dimensions of the drive systems; 2) the increase of the drive systems reliability and obtaining their higher fault-tolerance abilities; 3) the minimization of the motion speed pulsations and its oscillations, etc. The results of the researches received by the authors of this paper show that the use of the multiphase (i.e. having the number of phases more than four) inverter-fed induction motors in these traction systems is the most effective way of solving the above mentioned problems. In this case the motion speed oscillations can be decreased only by the increase of the drive phase number without any change in the inverter control algorithm. In addition, the application of some non-traditional control methods in the multiphase asynchronous traction drive system of a railway vehicle allows to decrease the mass-and-overall dimensions of the system and to improve its reliability and some other technicaland economic characteristics
\end{abstract}

Key words : Multiphase, Inverter-fed, Asynchronous drive, Traction system, Railway vehicle

\section{Introduction}

At present among the most important problems in the field of traction drive systems of railway vehicles are the following:

- the minimization of the mass-and-overall dimensions of the drive systems;

- the increase of the drive systems reliability and obtaining their higher fault-tolerance abilities;

- the minimization of the motion speed pulsations and its oscillations (including post-fault situations), etc.

The results of researches received by the authors of this paper show that the use of the multiphase (i.e. having the number of phases $m>4$ ) inverter-fed induction motors in these traction systems is the most effective way of solving the above mentioned problems because multiphase inverter-fed asynchronous drives have better technicaland-economic characteristics and potentials for their further improvement than the 3-phase ones [19-31].

\footnotetext{
Corresponding author: Department of Mining Machines and Complexes, Siberian Federal University, Krasnoyarsk, Russia

E-mail : multypha@mail.ru
}

\section{Advantages of Multiphase Inverter-Fed Asynchronous Drives at Traditional Control}

Until recently it was considered that the main advantages of the multiphase asynchronous drives over the 3phase ones are an opportunity for expansion of rotation speed regulation range down from the nominal speed value, an opportunity for the decrease of mass-and-overall dimensions of the filter in the input circuit of a voltage inverter, the decrease of the electrical losses in an induction motor rotor circuit and some others.

For example, the results of the investigations [3,19] show that even if the classical 180-degree algorithm of inverter control mode is used, the increase of the induction motor drive phase number $m$ leads to the decrease of the amplitude and increase of the frequency of the oscillations of the motor torque and inverter input circuit current (see Figs. 1 and 2). That allows to expand the rotor speed regulation range down from the nominal speed value (for example, by about $100 \%$ if the phase number rises from 3 to 9) and to decrease the mass-and-overall dimensions of the filter in the inverter input circuit (for example, about 


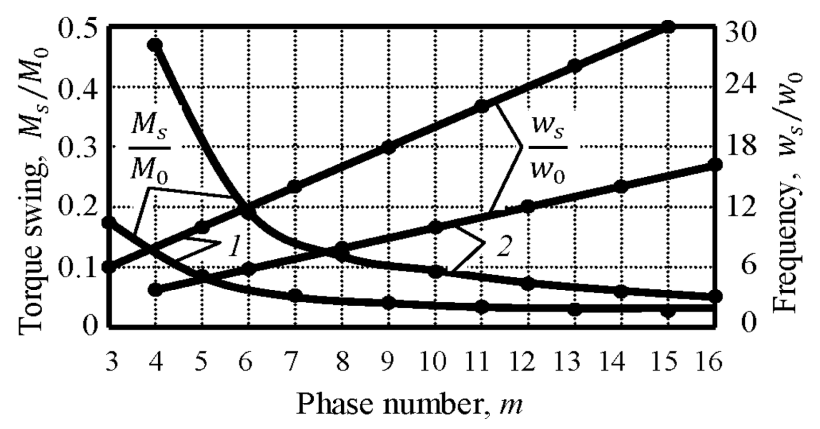

Fig. $1 \mathrm{~m}$-dependences of torque swing $\left(M_{S}\right)$ and frequency $\left(w_{S}\right)$ of torque and inverter input current oscillations for the case when the classical 180-degree algorithm of inverter control is used, where the line 1 is for odd $m$, line 2 is for even $m, M_{0}$ is the torque constant component, and $w_{0}$ is the inverter output voltage frequency

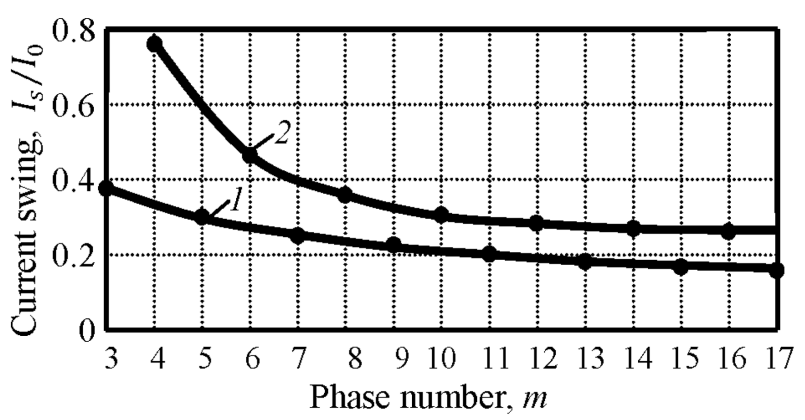

Fig. $2 m$-dependences of inverter input current swing $\left(I_{S}\right)$ for the case when the classical 180-degree algorithm of inverter control is used, where the line 1 is for odd $m$, line 2 is for even $m$, and $I_{0}$ is the inverter input current constant component

2.5-3.0 times decrease if the phase number $m$ rises from 3 to 9 ).

Thus the application of the multiphase inverter-fed asynchronous drives in the field of railway vehicles is expedient even if the control by frequency converter is carried out according to the traditional control methods (i.e. without any change in the magnitude of the phase shift (i.e. electrical angle) between the nearest (in time) phase voltages of a multiphase inverter).

\section{Non-Traditional Control of Multiphase Inverter-Fed Asynchronous Drives}

\subsection{Additional control potentials of multiphase inverter-fed asynchronous drives}

The increase of the phase number $m$ more than four allows not only to improve a number of technical-and-economic characteristics of the inverter-fed linear and non-linear induction motors [1-4,6-10,19], but also to open the way for the design of the electrical drives having radically new properties and possibilities. It is conditioned by the possibility for the use of some non-traditional motor control methods in the induction drive system which appears when $m 5$ [20-27,29,30]. These non-traditional control methods cannot in principle be used when the inverter-fed linear motor phase number is equal to three or four.

The application of these non-traditional control methods increases the expedience of the use of the multiphase inverter-fed asynchronous drives in the field of railway vehicles.

The greater control potentials of the multiphase inverterfed induction drives are explained by the following. If $m$ is equal to three or four, the drive system has two variables of operating influence on the electromagnetic processes occurring in the system - the phase voltage magnitude, and its frequency. In the case, when $m>4$, one more variable of operating influence may be added to the above mentioned ones - the magnitude of the phase shift (i.e. electrical angle) between the nearest (in time) phase voltages of a multiphase inverter. The change of this shift can be obtained by mere application of the corresponding software, namely, by the corresponding change in the inverter transistors control algorithm (i.e. by the change of the moment in which the corresponding transistors are switched on and switched off) without application of any additional electronic or mechanical switchers, or some complicated motor winding sets.

The possibility of the above mentioned phase shift change results in the extension of the set of the motor control methods by adding to this set a number of non-traditional ones which may be used in the multiphase drive systems.

In particular, the over-phase control method (OPM) is one of the above-mentioned non-traditional ones. It was developed by the authors of this paper for the use in the field of both linear and non-linear inverter-fed multiphase (i.e. having the phase number $m 5$ ) induction motor drives. Some properties and peculiarities of OPM were presented [20-30].

\subsection{General description of over-phase con- trol method}

The essence of the control according to OPM is that in this case the electrical angles $\alpha$ between the voltages (or currents) of the nearest (in time) phases of inverter are increased by a factor of $H$ (in comparison with any traditional control method) without any change of the inverter voltage (or current) amplitude and frequency, i.e. in this case $\alpha_{H}=H \cdot \alpha_{T}$, where $H$ is some whole number, $\alpha_{T}$ is the value $\alpha$ when some traditional control method is used ( $\alpha_{T}$ 


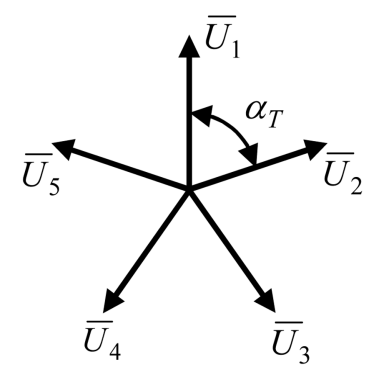

(a)

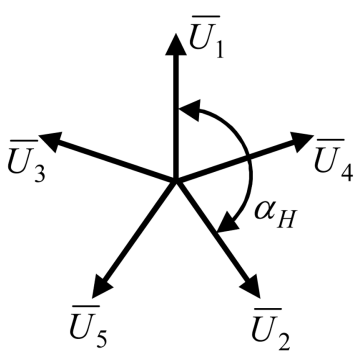

(b)
Fig. 3 5-phase system of the inverter output voltages: (a) $H=1$, (b) $H=2$

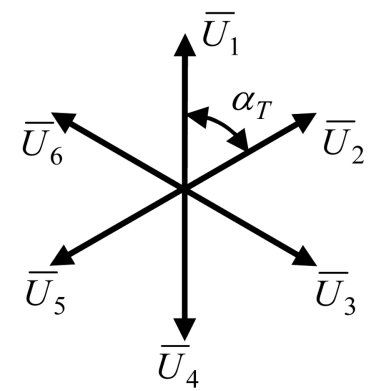

(a)

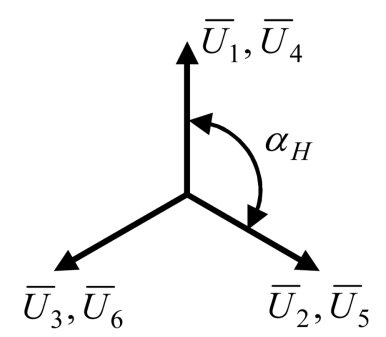

(b)
Fig. 4 6-phase system of the inverter output voltages:

(a) $H=1$, (b) $H=2$

$=2 \pi / m$ ), and $\alpha_{H}$ is the value $\alpha$ when OPM is used (see Figs. 3 and 4).

The change of this phase shift can be obtained by mere application of the corresponding software, namely, by the corresponding change in the inverter transistors control algorithm (i.e. by the change of the moment in which the corresponding transistors are switched on and switched off) without application of any additional electronic or mechanical switchers, or some complicated motor winding sets.

OPM can be used both in mono- and multi-motor drive systems of railway vehicles. In particular, it can be used in the multi-motor drive systems fed by one or more frequency converters for distribution of traction forces between the motorized wheels of a wheeled vehicle (see Fig. 5), and for obtaining fault-tolerance abilities of drive system in post-fault situations.

Generally speaking, two ways of realization of OPM are possible:

Way 1. By the corresponding change in the switching algorithm of the inverter transistors without any changes in the traditional scheme of the inverter (i.e. without application of any electronic or mechanical switchers of the motor

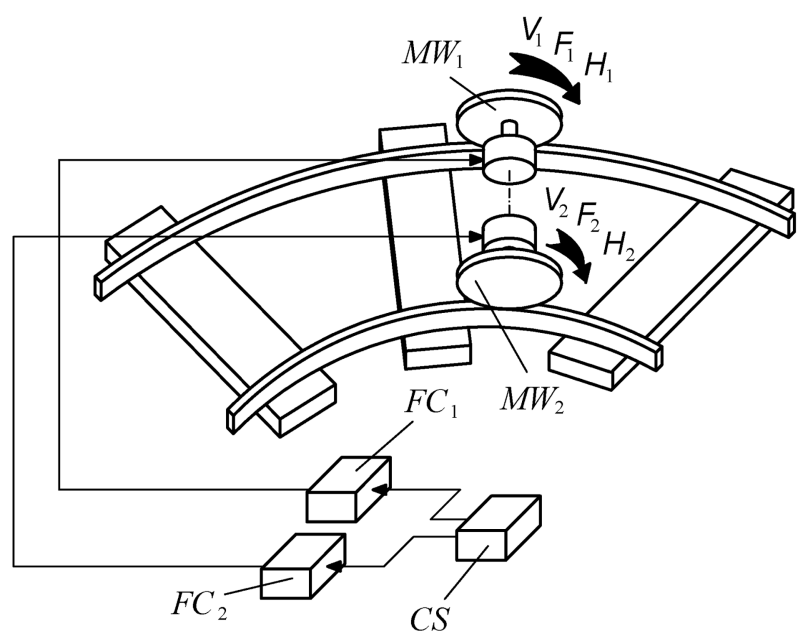

Fig. 5 Distribution of torques and rotation speeds between the motorized wheels of a wheeled railway vehicle: $M W$ is motorized wheel, $F C$ is frequency converter, $C S$ is control system, $V$ is rotation speed, $F$ is motor torque, and $H$ is parameter of OPM

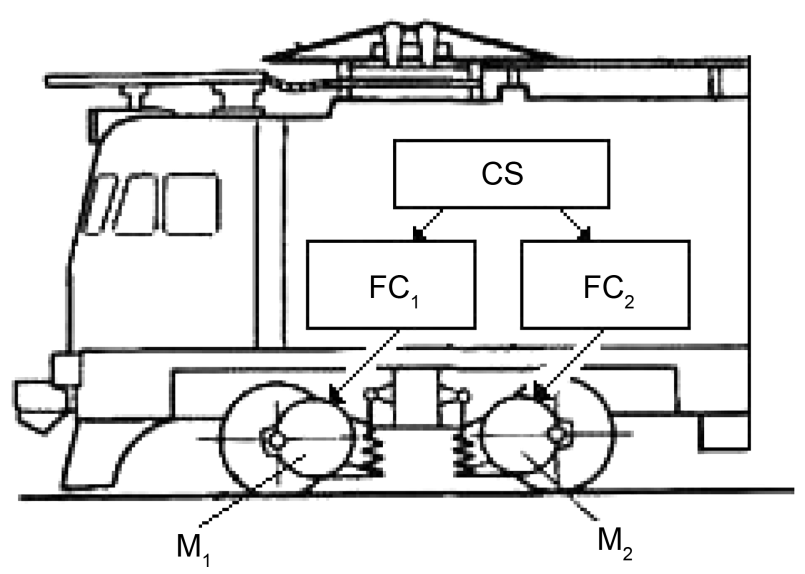

Fig. 6 Two-motor drive system of a railway wheeled vehicle: $M$ is induction motor, $F C$ is frequency converter, and $C S$ is control system

stator phase windings or their sections). The first way can be used both in mono- and multi-motor drive systems of railway vehicles when each motor is fed by own individual frequency converter (see Fig. 6).

Way 2. By the use of an electronic or mechanical phase commutator placed between a frequency converter and an induction motor. In this case the change in the OPM parameter $H$ is reached not by any change in the electrical angles $a$ between voltages (or currents) of the nearest phases of inverter, but by the change in the version of connection output terminals of inverter to the terminals of the motor stator phase windings.

In this case the multiphase inverter has traditional 
scheme and operates at the sole value of the parameter $H$ : $H=1$. The change in the value of the parameter $H$ is achieved by the above mentioned phase commutator placed between an inverter and a motor.

The second way is more expedient for the multi-motor drive systems of railway vehicles, in which different motors fed by one frequency converter may operate at different values of the parameter $H$ at the same moment (for example, for distribution of traction forces between the motorized wheels of a wheeled vehicle).

The range of the parameter $H$ (including its maximal value), which can be achieved in the given drive system, depends on the phase number of the system and on a motor stator winding type.

The change of the parameter $H$ results in the change of the filtering properties of the inverter-fed multiphase asynchronous drive. In particular, the numbers of the harmonics, which take part in the creation of the magnetic field in a motor air gap, are described by the following equation:

$$
H \cdot c \pm n / p=b \cdot m
$$

where $c$ is the number of the phase voltage (or current) harmonic (i.e. the number of the time harmonic), $n$ are the numbers of the harmonics of the functions which describe a space distribution of the mutual inductances between motor phase windings (i.e. the numbers of the space harmonic), and the coefficient $b=0, \pm(1,2,3, \ldots), p$ is number of motor poles pairs.

The magnetic fields created in a motor air gap by the harmonics, numbers of which does not satisfy equation (1), cancel each other.

The equation (1) is derived as a result of the decision of the equations that describe the electromagnetic processes taking place in $m$-phase induction motor $[19,20]$.

OPM has two kinds - over-synchronous control method (OSM) and phase-pole control one (PPM). The use of these OPM kinds allows achieving the following two effects:

- the increase of the linear motor movable secondary element motion speed over its synchronous value $V_{S}$ which is conditioned by the inverter output voltage frequency and the motor pole number (OSM).

- the increase of the motor linear forces without any change in the amplitude and frequency of the inverter output voltage (PPM) [20-30].

OSM differs from PPM in the following: when OSM is used, the spectrum of the function, which describes the space distribution of the mutual inductances between motor phase windings, does not change for all parameter $H$ values which have to be realized in the given drive system. When PPM is used, the spectrum of the above-
Table 1. Values of the Parameter $C_{O}$

\begin{tabular}{|c|c|c|c|c|c|c|c|c|c|c|}
\hline \multirow{2}{*}{$\mathrm{m}$} & \multicolumn{10}{|c|}{$\mathrm{H}$} \\
\hline & & 2 & 3 & 4 & 5 & 6 & 7 & 8 & 9 & 10 \\
\hline 5 & $3^{*}$ & $2^{* *}$ & 2 & - & - & - & - & - & - & - \\
\hline 7 & & 3 & 2 & 2 & - & - & - & - & - & - \\
\hline 8 & & - & 3 & - & - & - & - & - & - & - \\
\hline 9 & & 5 & - & 2 & 2 & - & - & - & - & - \\
\hline 10 & & - & 3 & - & - & - & - & - & - & - \\
\hline 11 & & 5 & - & 3 & 2 & 2 & - & - & - & - \\
\hline 13 & & 7 & - & 3 & - & 2 & 2 & - & - & - \\
\hline 14 & & - & 5 & - & 3 & - & - & - & - & - \\
\hline 15 & & 7 & - & - & - & - & 2 & 2 & - & - \\
\hline 16 & & - & 5 & - & 3 & - & - & - & - & - \\
\hline 17 & & 9 & - & - & - & 3 & - & 2 & 2 & - \\
\hline 19 & & 9 & - & 5 & - & 3 & - & - & 2 & 2 \\
\hline 20 & & - & 7 & - & - & - & 3 & - & - & - \\
\hline 21 & & - & - & 5 & - & - & - & - & - & 2 \\
\hline 22 & & - & 7 & - & - & - & 3 & - & - & - \\
\hline 23 & & 11 & - & - & - & - & - & 3 & - & - \\
\hline 24 & & - & - & - & 5 & - & - & - & - & - \\
\hline
\end{tabular}

* - When the spectrum of the inverter output voltage contains only odd harmonics.

${ }^{* *}$ - When the spectrum of the inverter output voltage contains both even and odd harmonics.

mentioned function changes during $H$ value changing process.

\section{Application of OSM}

When OSM is used, the linear motor movable secondary element motion speed $V$ may be increased by a factor of some whole number $C_{O}$ over its synchronous value $V_{S}$, i.e. $V=C_{O} \cdot V_{S}$ (without any change in the motor pole length and inverter output voltages frequency), where

$$
C_{O}=(m \pm 1) / H
$$

The values of the parameter $C_{O}$, which can be achieved for $m \in[5 ; 24]$ in the case when OSM is used, are given in Table 1 .

As an example the mechanical characteristics of a multiphase linear inverter-fed induction motor are shown in Fig. 7 on a per-unit basis for the case when the traditional control method (line 1) and OSM (line 2) are used, where $F$ is linear traction force (or torque, when the motor stator is bow-shaped).

Hereinafter the comparison of the corresponding charac- 


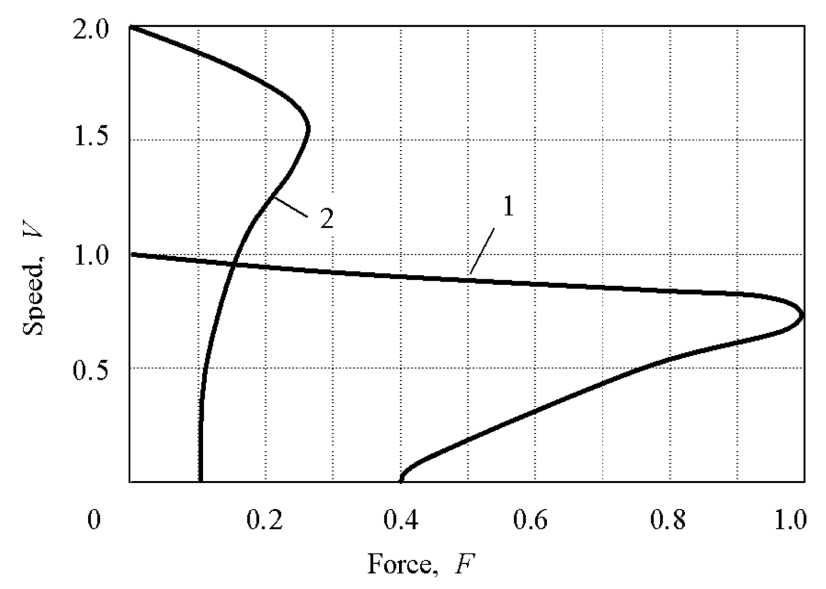

Fig. 7 Mechanical characteristics of a multiphase linear inverter-fed induction motor on a per-unit basis: (1) natural characteristic, when the traditional control method is used $(H=1)$, and (2) when OSM is used $(H=2)$

teristics of the multiphase induction drives is being carried out at fulfillment of the following condition: $P_{1}=$ const at $H=$ var, where $P_{1}$ is the drive system power input.

Theoretically (when $m \rightarrow \infty$ ) the use of OSM allows to increase the motion speed $V$ over the value $V_{S}$ without limit. However the use of OSM is accompanied by considerable decrease of the motor energy efficiency.

OSM can be used both for flat and for tubular design types of the multiphase linear motor. However in the case of flat design type it is necessary to use the phase stator windings having number of slots per a pole and a phase no less than two to ensure the possibility of OSM application.

\section{Application of PPM}

During PPM application process, when the parameter $H$ changes, the effect adequate to the synchronous change of the drive phase number and number of motor poles appears.

PPM being used, the following equation is fulfilled:

$$
p_{e} \cdot m_{e}=p \cdot m=\text { const }
$$

where $m$ is real value of the phase number of the inverter multiphase AC drive system, $m_{e}$ is equivalent (observed) value of the drive system phase number, $p$ is real number of the motor poles pairs, and $p_{e}$ is equivalent (observed) number of the motor poles pairs $\left(p_{e}=p \cdot H\right)$.

The values of parameter $p_{e}$ for $m \in[6 ; 30]$, which can be achieved when PPM is used, are given in Table 2 for the case when $p=1$.

Designing motor winding, it is necessary to consider,
Table 2 Values of the parameter $p_{e}$ forgiven values $m$ and $p=1$

\begin{tabular}{|c|c|c|c|c|c|c|c|c|c|}
\hline \multirow{2}{*}{$m$} & \multicolumn{9}{|c|}{$p_{e}$} \\
\hline & 2 & 3 & 4 & 5 & 6 & 7 & 8 & 9 & 10 \\
\hline 6 & & & & & & & & & \\
\hline 8 & & & & & & & & & \\
\hline 9 & & & & & & & & & \\
\hline 10 & & & & & & & & & \\
\hline 12 & & & & & & & & & \\
\hline 14 & & & & & & & & & \\
\hline 15 & & & & & & & & & \\
\hline 16 & & & & & & & & & \\
\hline 18 & & & & & & & & & \\
\hline 20 & & & & & & & & & \\
\hline 21 & & & & & & & & & \\
\hline 22 & & & & & & & & & \\
\hline 24 & & & & & & & & & \\
\hline 25 & & & & & & & & & \\
\hline 26 & & & & & & & & & \\
\hline 27 & & & & & & & & & \\
\hline 28 & & & & & & & & & \\
\hline 30 & & & & & & & & & \\
\hline
\end{tabular}

that the following conditions must be fulfilled for attaining the opportunity of PPM realization without any deterioration of drive system technical-and-economic characteristics (in particular, system efficiency) in comparison with the case when $H=1$ :

Condition 1: The space harmonics having numbers $n=p \cdot H$ must be contained in the spectrum of the function describing the space distribution of the mutual inductances between motor phase windings for all parameter $H$ values which have to be realized in the given drive system.

Condition 2: When $H>1$, the amplitudes of the above mentioned space harmonics (i.e. having numbers $n=p \cdot H$ ) must have the values being not less than those at $H=1$.

A number of the design versions of linear and non-linear motors and their windings, the use of which allows to provide the above-mentioned conditions, has been worked out by the author of this paper. Some of these designs are described in [21-29, 31].

The combined application of PPM and the classical frequency control method allows obtaining the following advantages over the traditionally controlled drive systems without any rise in the motor magnetic circuit magnetization magnitude. 


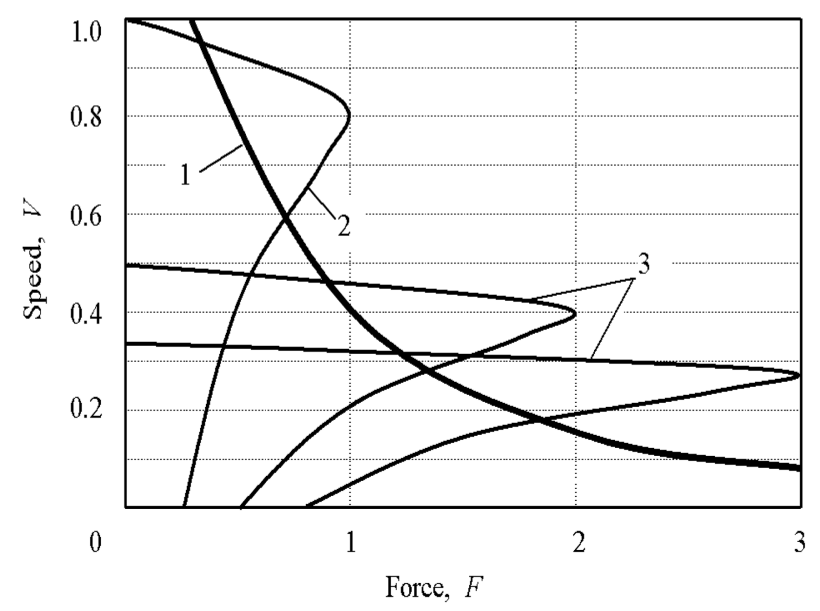

Fig. 8 Descending mechanical characteristic of motor load (1) and mechanical characteristics of a multiphase linear inverter-fed induction motor on a per-unit basis: line (2) is natural characteristic, when the traditional control method is used $(H=1)$, and line (3) is the characteristic when PPM is used ( $H=2$ and $H=3$ )

\subsection{Increase of motor maximal and starting linear forces}

The set of motor mechanical characteristics, which differ in their magnitudes of the synchronous motion speed, and maximal and starting linear traction forces (or torques, when the motor stator is bow-shaped) from each other, are obtained by the regulation only of the parameter $H$ without any change in the frequency and amplitude of inverter output voltage or current (see lines (2) and (3) in Fig. 8).

In this case the synchronous speed value $V_{S}$ and maximal linear traction force (torque) $F_{m}$ of an AC motor are described by the following formulae:

$$
\begin{aligned}
& V_{S . H}=60 \cdot c_{m} \cdot f_{O} / h_{m}=V_{S . T} / H \\
& F_{m . H}=h_{m} \cdot H \cdot F_{m . T}
\end{aligned}
$$

where $V_{S . T}$ is the synchronous motion speed when the traditional control method is used (i.e. when $H=1$ ), $V_{S . H}$ is the same parameter when PPM is used (i.e. when $H>1$ ), $F_{m . T}$ is maximal value of motor linear traction force (torque) when the traditional control mode is used (i.e. when $H=1), F_{m . H}$ is the same parameter when PPM is used (i.e. when $H>1$ ), $f_{O}$ is the frequency of the inverter output voltage,

$$
h_{m}=\left(m^{2}-A_{m} \cdot H^{2}\right) /\left(m^{2}-B_{m}\right)
$$

$A_{m}=0$ for even values of phase number $m_{e}=p \cdot m / p_{e}, A_{m}=1$ for odd values of the parameter $m ; B_{m}=0$ for even values of $m, B_{m}=1$ for odd values of $m, c_{m}$ is the least value of $c$ satisfying equation (1), $n_{m}$ is the least value of $n$ satisfying

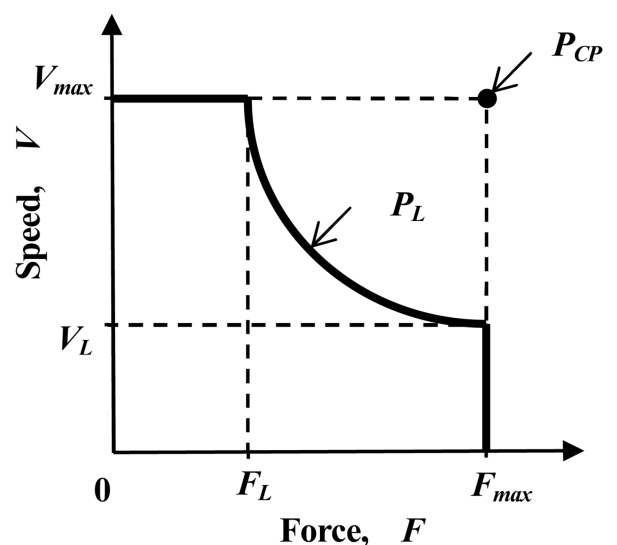

Fig. 9 Restrictedly-descending mechanical characteristic of motor load

equation (1) at $c=c_{m}$.

Formula (6) is true for the case when the type of a motor stator phase windings connection is "the star without a neutral conductor". If this connection type is "the star with a neutral conductor", $h_{m}=1$ for all values of the parameters $m, H$, and $m_{e}$.

Thus in the case when PPM is used the considerable increase of the maximal and starting forces (or torques, when the motor stator is bow-shaped) of a multiphase AC linear motor can be provided. This effect may be obtained in all the range of motor secondary element speed regulation, but in this case the frequency and amplitude of inverter output voltage must be increased by a factor the value of which depends on the parameter $H$ value.

\subsection{Decrease of motor power rating and mass-and-overall dimensions}

Load mechanisms of traction drives have descending mechanical characteristics (see line (1) in Fig. 8). For example, the motor loads in the drives of traction systems, oil deep-well pumps, etc. have such mechanical characteristics.

If the mechanical characteristic of a linear motor load mechanism is descending, the combined application of PPM and the classical principle of frequency control in the drive system allows to use the motors having less power rating than in the case when the frequency control method is only used (according to the principle $U_{O} / f_{O}=$ const). The degree of this motor power rating decrease depends on the phase number $m$ of the drive system and on the concrete type of the load mechanical characteristic.

For example, if the mechanical characteristic of a linear motor load mechanism is restrictedly-descending (see Fig. 9) and the routine frequency control method is only used (according to the principle $U_{O} / f_{O}=$ const), the motor 
power output is equal to $P_{C P}$ (the corner power), where $P_{C P}=F_{\max } \cdot V_{\max }$. If in this case PPM is used, the motor power output may be decreased to the value $P_{L}=F_{L} \cdot V_{L}$, i.e. by a factor of $K_{P . D}=\left(F_{\max } \cdot V_{\max }\right) /\left(F_{L} \cdot V_{L}\right)$. For example, if $F_{\text {max }}=2 F_{L}$ and $V_{\text {max }}=2 V_{L}, K_{P . D}=4$.

Since the motor power rating can be decreased, so the mass-and-overall dimensions, manufacturing cost of the machine, and the inertial moment of a motor rotor diminish as well.

\subsection{Prospects for the use of PPM in the field of fault-tolerant drive systems of rail- way vehicles}

It is profitable to use PPM (in a complex with the increase of inverter voltage frequency by a factor of $H$ ) for the development of the multiphase inverter-fed induction motor drive systems of railway vehicles having:

- the greater time of operating to total failure than the analogous 3-phase systems;

- the less motor mass-and-overall dimensions than the motor of the fault-tolerant multiphase (i.e. having $m>4$ ) drive systems that PPM is not used in.

The necessity of the PPM use causes some requirements to the inverter and induction motor designs. In particular, they must have the phase number $m \geq\left(m_{m} \cdot H_{m}=6\right)$, where $m_{m}$ is the minimal value of $m$ required for obtaining possibility of the PPM use, $m_{m}=3, H_{m}$ is the minimal value of $H$ required for obtaining possibility of the PPM use, $H_{m}=2$.

Nowadays a number of research and design works are devoted to development of 3- and multiphase fault tolerant AC drives [5, 12-18].

Taken alone, the increase of the phase number more than five (without any changes in the system of inverter phase voltages) does not ensure any essential increase of the inverter-fed AC drive system reliability (contrary to some erroneous contentions [11]).

The increase of the system phase number more than five allows to increase the inverter-fed induction motor drive system reliability only in the two following cases (i.e. when the following development and post-fault control strategies are used):

Strategy 1. If in post-fault situations the output power of a multiphase (i.e. having $m>4$ ) inverter per phase can be increased by the factor $N_{P}$ (without the application of PPM in post-fault situations) by the corresponding increase in phase voltages and currents, where $N_{P} \approx m / m_{N}=m /(m-$ $\left.m_{F}\right), m_{N}$ is the number of the intact phases of an inverter (or an induction motor), $m_{N}=m-m_{F}, m_{F}$ is the number of the damaged phases of an inverter (or motor).

Every concrete drive system in every concrete situation (i.e. at the concrete motor load) can operate only till the moment that some maximal number $m_{\text {Fmax }}$ of phases will be damaged to. The increase of the time of the drive system operating to failure may be determined by the coefficient $K_{T . O}$ :

$$
K_{T . O}=T_{O}\left(m, m_{F . m a x}\right) / T_{O .3}=3\left(m-m_{N}\right) / m=3\left(N_{P}-1\right) / N_{P},(7)
$$

where $T_{\mathrm{O}}\left(m, m_{F \max }\right)$ is the time of the $m$-phase drive system operating till the moment that $m_{F \max }$ phases will be damaged to, $T_{\mathrm{O} .3}$ is the time of the 3-phase drive system operating to total failure.

Below such development and post-fault control strategy is termed "The base development and post-fault control strategy (BPFS)". It is necessary to use the inverter and motor windings wires, motor magnetic circuits, and inverter power gate elements (for example, transistors), which are designed with a reserve of the corresponding voltages, currents and magnetic induction magnitudes, for obtaining this strategy application possibility in the given inverter-fed induction motor drive system [18].

It is obviously that the application of this strategy is accompanied by the increase of mass-and-overall dimensions and manufacturing cost of the inverter-fed induction motor drive systems. This increase degree is approximately described by the coefficient $N_{P}$.

Because of this the use of the first strategy is profitable only if $m_{F} \leq m / 2$, i.e. if $N_{P} \leq 2$. If $m_{F}>m / 2$, the cold redundancy (i.e. the use of reserve motor, for example) is more profitable than the application of BPFS.

Strategy 2. If the PPM-based strategy of development of the fault-tolerant inverter-fed induction motor drive system is used for the increase of time to total failure (i.e. for the increase of reliability) of the system. One of the key elements of this strategy is the use of peculiar inverter control algorithms for the decrease of the motor torque (linear force) oscillation magnitude in abnormal (i.e. post-fault) situations [28].

If PPM-based strategy is used, the increase of the time of the drive system operating to failure may be determined according to formula (7).

For performance evaluation of the PPM-based strategy of development of fault tolerant inverter-fed multiphase inverter-fed induction motor drive systems, which is called "PPM-based strategy" below, the parameters $K_{I} \approx 1 / H^{0.5}$ and $K_{U} \approx H^{0.5}$ were determined, where the parameter $K_{I}$ shows in what times the motor phase currents may be increased when the PPM-based strategy is used in comparison with the case when BPFS is used, and the parameter $K_{U}$ shows in what times the motor phase voltages must be increased when the PPM-based strategy is used in comparison with the case when BPFS is used. 
The parameters $K_{I}$ and $K_{U}$ were determined for the case when in abnormal (i.e. post-fault) situation the torque created by the motor stator winding set, and speed of the motor secondary element should be the same as well as they were in normal (i.e. non-fault) situation.

The parameters $K_{I}$ and $K_{U}$ allows to evaluate approximately the change of mass-and-overall dimensions and manufacturing cost of the motor and inverter when worked out PPM-based strategy is used in comparison with the case when BPFS is used:

- the mass-and-overall dimensions and manufacturing cost of the motor may be decreased approximately by a factor of $H^{0.5}$ (but no more this value) in passing from BPFS to the PPM-based strategy;

- the mass-and-overall dimensions and manufacturing cost of inverter must be increased approximately by a factor of $H^{0.5}$ (but no more this value) in passing from BPFS to the PPM-based strategy.

Thus when passing from BPFS to the PPM-based strategy, gain in the motor mass-and-overall dimensions and its manufacturing cost may be achieved by loss in the inverter corresponding technical-and-economic parameters.

For example, if $m=6$ and BPFS is used, and the system must operate till the moment that $m_{F \cdot \max }=3$ phases will be damaged to, the time $T_{\mathrm{O}}\left(m, m_{F}\right)$ is 1.5 greater than the time $T_{0.3}$ of the 3-phase drive system operating to total failure (i.e. $K_{T . O}=1.5$ ). However in this case the mass-andoverall dimensions and manufacturing cost of the whole inverter-fed induction motor drive system and each of its elements (in particular, motor and inverter) will rise approximately by a factor of $N_{P}=2$ (in comparison with the 3-phase system). If to pass from BPFS to the PPMbased strategy with $H=2$, it is possible to decrease massand-overall dimensions and manufacturing cost of the motor approximately by a factor of $H^{0.5}=2^{0.5} \approx 1.414$ (however in this case the mass-and-overall dimensions and manufacturing cost of the inverter will rise approximately by a factor of 1.414). Ultimately, the change in the massand-overall dimensions and manufacturing cost after the phase number increase and application of PPM-based strategy is as follows:

- the mass-and-overall dimensions and manufacturing cost of the motor must be increased approximately by a factor of 1.4 (in comparison with the 3-phase system),

- the mass-and-overall dimensions and manufacturing cost of inverter must be increased approximately by a factor of 2.8 (in comparison with the 3-phase system).

For a number of vehicles, in which the system reliability increase and the motor mass-and-overall dimensions decrease are very important, the PPM-based strategy is more preferable than BPFS. In these cases the field of the
PPM-based strategy profitable application may be extended up to $m_{F} \leq\left(m \cdot H^{0.5}\right) / 2$.

Thus the application of PPM-based strategy in a number of cases can allow:

- to increase the time of no-failure operation of a traction drive system of a railway vehicle by a factor of $H^{0.5}$ in comparison with the case when BPFS is used;

- or to decrease the mass-and-overall dimensions and manufacturing cost of a traction drive system of a railway vehicle without any decrease of the fault-tolerance abilities of the system.

\section{Conclusion}

The application of the OPM-controlled multiphase inverter-fed asynchronous drives is expedient in both fields of the railway vehicles - in the field of wheeled vehicles, and in the field of vehicles based on the use of the magnetically levitated systems (MAGLEV).

The use of the OPM-controlled multiphase inverter-fed induction motor drives in these fields will allow to carry out the traction drive systems of the railway vehicles having high fault-tolerance abilities and less mass-and-overall dimensions than analogous systems based on the use of the 3-phase AC drives.

\section{Acknowledgement}

This work was supported in part by the Ministry of Education and Science of the Russian Federation under Grant $\Pi 232$.

\section{References}

1. Ward, E.E. and Härer, H. (1969). "Preliminary investigation of an inverter-fed 5-phase induction motor," IEE Proceedings, Vol. 116, pp. 980-984.

2. Nelson, R.H. and Krause, P.C. (1974). "Induction machine analysis for arbitrary displacement between multiple winding sets," IEEE Transactions on Power Apparatus and Systems, Vol. 93, pp. 841-848.

3. Klingshirn, E.A. (1983). "High phase order induction motors," IEEE Transactions on Power Apparatus and Systems, Vol. 102, No. 1, pp. 47-59.

4. Ferraris, P. and Lazzari, M. (1983). "Phase numbers and their related effects on the characteristics of inverter fed induction motor drives," Proceedings of IEEE Industry Applications Society Annual Meeting IAS, Mexico City, Mexico, pp. 494-502.

5. Fu, J.-R. and Lipo, T.A. (1994). "Distorbance-free operation of a multiphase current-regulated motor drive with an opened phase," IEEE Transactions on Industry Applica- 
tions, Vol. 30, No. 5, pp. 1267-1274.

6. Munoz, A.R. and Lipo, T.A. (2000). "Dual stator winding induction machine drive," IEEE Transactions on Industry Applications, Vol. 36, pp. 1369-1379.

7. Tenconi, A., Grieco, G., Lazzari, M. and Profumo, F. (2001). "Analytical and numerical computation of RMS current stress on the DC link capacitor in multiphase voltage source PWM inverters," Proceedings of European Conference on Power Electronics and Applications EPE'2001, Graz, Austria, paper No. PP01087, CD-ROM.

8. Hadiouche, D. (2001). "Contribution à l'étude de la machine asynchrone double étoile: modélisation, alimentation et structure," Université Henri Poincaré, Nancy-I, France, 192 p. (in French).

9. Toliyat, H.A., Shi, R. and Xu, H. (2002). "Multi-phase induction motor drive system and method," U.S.A. Patent No. US 6426605B1.

10. Wang, C.-C. (2005). "Analysis and design of a six-phase permanent-magnet synchronous motor drive," National Taiwan University of Science and Technology, Taiwan, $89 \mathrm{p}$.

11. Glukhov, D.M. (2005). "Simulation of multiphase induction motors in abnormal situations," Ph.D. Dissertation, Tomsk Polytechnical University, Tomsk, Russia, 230 p. (in Russian).

12. Yeh, C.-C. and Demerdash, N. (2007). "Fault tolerant operations in adjustable-speed drives and soft starters for induction motors," Proceedings of 38th IEEE Power Electronics Specialists Conference PESC'2007, Orlando, Florida, U.S.A., pp. 1942-1949.

13. Yeh, C.-C. and Demerdash, N. (2007). "Induction motor drive systems with fault tolerant inverter-motor capability," Proceedings of IEEE International Electric Machines and Drives Conference IEMDC'2007, Antalya, Turkey, pp. 1451-1458.

14. Zhao, W., Cheng, M., Hua, W. and Jia, H. (2008). "A redundant flux-switching permanent magnet motor drive for faulttolerant applications," Proceedings of IEEE Vehicle Power and Propulsion Conference VPPC'2008, Harbin, China, pp. $1-6$.

15. Wu, T.-T. (2009). "Post-fault control strategy for six-phase permanent-magnet synchronous motor drives," National Taiwan University of Science and Technology, Taiwan, 85 p.

16. Yeh, S.-N., Hwang, J.-C., Wu, T.-T. and Liu, C.-T. (2009). "Post-fault control strategy for six-phase permanent-magnet synchronous motor drives," Proceedings of 30th R.O.C. National Conference on Energy, November 28-29, 2009, Taoyuan, Taiwan, 5 p., CD-ROM.

17. Khan-on, S., De Lillo, L., Empringham, L. and Wheeler, P.W. (2010). "A fault-tolerant matrix converter motor drive under open phase faults," Proceedings of 5th IET International Conference on Power Electronics, Machines and Drives PEMD'2010, Brighton, U.K., pp. 1-6.

18. Odnokopylov, I., Obraztsov, K., Odnokopylov, G. and Zentner, J. (2011). "Novel fault-tolerant concept for linear induction motor drives," Proceedings of 8th International
Symposium on Linear Drives for Industry Applications LDIA'2011, Eindhoven University of Technology, Eindhoven, the Netherlands, paper No. 215, 6 p., CD-ROM.

19. Brazhnikov, A.V. (1985). "Multiphase inverter electric drive with various versions of induction motor rotor," Ph.D. Dissertation, Tomsk Polytechnical Institute, Tomsk, Russia, 210 p. (in Russian).

20. Brazhnikov, A.V. (1993). "Additional resources of control of multiphase inverter drives," Proceedings of 7th International Conference on Electrical Machines and Drives ELMA'93, Varna, Bulgaria, pp. 325-332.

21. Brazhnikov, A.V. and Dovzhenko, N.N. (1994). "Beyond routine control of multiphase inverter drives," Proceedings of International Conference on Power Electronics, Motion Control and Associated Applications PEMC'94, Warsaw, Poland, Vol. 1, pp. 99-104.

22. Brazhnikov, A.V. and Dovzhenko, N.N. (1998). "Control potentials and advantages of multiphase AC drives," Proceedings of 29th IEEE Power Electronics Specialists Conference PESC'98, Fukuoka, Japan, Vol. 2, pp. 2108-2114.

23. Brazhnikov, A.V. and Belozyorov, I.R. (2011). "Over-phase control of inverter multiphase AC linear drives," Proceedings of 8th International Symposium on Linear Drives for Industry Applications LDIA'2011, Eindhoven University of Technology, Eindhoven, the Netherlands, paper No. 172, 6 p., CD-ROM.

24. Brazhnikov, A.V., Belozyorov, I.R. and Molokitin, S.A. (2011). Inverter-fed multiphase AC linear motors under nontraditional control, Proceedings of 21st International Conference on Magnetically Levitated Systems and Linear Drives MAGLEV'2011, Daejeon, Korea, paper No. PLE-04, 5 p., CD-ROM.

25. Brazhnikov, A.V., Belozyorov, I.R. and Molokitin, S.A. (2011). Energy efficiency invariance laws acting in the field of multiphase inverter-fed AC linear motors, Proceedings of 21st International Conference on Magnetically Levitated Systems and Linear Drives MAGLEV'2011, Daejeon, Korea, paper No. PLE-06, 4 p., CD-ROM.

26. Brazhnikov, A.V. and Belozerov, I.R. (2011). "Non-traditional control and advantages of multiphase $\mathrm{AC}$ inverter drives, Proceedings of IEEE International Conference on Energy, Automation and Signal ICEAS'2011, Bhubaneswar, Orissa, India, paper No. 6, 6 p., CD-ROM.

27. Brazhnikov, A.V. and Belozerov, I.R. (2011). Energy efficiency invariance laws acting in the field of multiphase AC inverter drives, Proceedings of IEEE International Conference on Energy, Automation and Signal ICEAS‘2011, Bhubaneswar, Orissa, India, paper No. 7, 6 p., CD-ROM.

28. Brazhnikov, A.V. (2011). "Method of design of control algorithms for multiphase inverters," Journal "Modern Problems of Science and Education", No. 6 (supplement "Technical Sciences"), p. 10.

29. Brazhnikov, A.V. and Belozyorov, I.R. (2012). "Space-temporal spectral relations and energy efficiency invariance laws acting in the field of inverter-fed multiphase AC drives," 
Prospects for the use of Multiphase Inverter-fed Asynchronous Drives in the Field of Traction Systems of Railway Vehicles

Proceedings of IET 6th International Conference on Power Electronics, Machines and Drives PEMD‘2012, Bristol, U.K., paper No. 0027, 6 p., CD-ROM.

30. Brazhnikov, A.V. and Belozyorov, I.R. (2012). "Over-phase control of inverter multiphase AC linear drives," Journal "Mechatronics", Elsevir Publishing Company, DOI 10.1016/ j.mechatronics.2012.02.003 (in press).

31. Brazhnikov, A.V. and Belozyorov, I.R. (2010). "Inverter multiphase induction motor drive under phase-pole control," Russian Patent No. RU 100863U1 (in Russian).

Received(March 13, 2012), Accepted(March 15, 2012) 